\title{
Economic burden of osteoporosis in the world: A systematic review
}

\author{
Asma Rashki Kemmak ${ }^{1}$, Aziz Rezapour*2 (D), Reza Jahangiri ${ }^{2}$, Shima Nikjoo ${ }^{2}$, Hiro Farabi², Samira Soleimanpour ${ }^{2}$ \\ Received: 15 Jan 2020 \\ Published: 12 Nov 2020
}

\begin{abstract}
Background: Osteoporosis is a skeletal disease that is associated with a reduction in bone mass and microstructures and deterioration of bone tissue. It is also associated with an increased risk of fracture that is the most important complication of osteoporosis. The knowledge about costs and economic aspects of osteoporosis plays an important role in making policies and planning measures for the prevention and management of this disease; hence, this study systematically investigated the available evidence on the costs associated with osteoporosis worldwide.

Methods: In this systematic review, electronic searches were performed on various online databases, including PubMed, Embase, Scopus, web of science, ProQuest, and Cochrane. The timeframe selected for searching articles was from 1980 to 2018.

Results: Of a total of 1989 papers, 28 papers were included in the study on the basis of inclusion criteria. Based on the data extracted from the mentioned studies, the mean age of people with osteoporotic fractures was 50 years, with the highest costs associated with hip fractures.

Conclusion: Our review indicated that the cost of osteoporosis carries a significant economic burden on countries in the world. The main cost drivers in this study were Fracture-related costs. The direct annual cost of treating osteoporotic fractures of people on average is reported to be between 5000 and 6500 billion USD in Canada, Europe and the USA alone, not taking into account indirect costs such as disability and loss of productivity. Prevention of this disease can significantly reduce the costs incurred by the health system.
\end{abstract}

Keywords: Cost of illness, Systematic review, Osteoporosis

Conflicts of Interest: None declared

Funding: This study was part of a research project that is supported by the health management and economics research center affiliated to Iran University of Medical Sciences (Project No. 97-3-48-12618 and Ethical Code. IR.IUMS.REC.1397.926).

\section{*This work has been published under CC BY-NC-SA 1.0 license. \\ Copyright $\odot$ Iran University of Medical Sciences}

Cite this article as: Rashki Kemmak A, Rezapour A, Jahangiri R, Nikjoo Sh, Farabi H, Soleimanpour S. Economic burden of osteoporosis in the world: A systematic review. Med J Islam Repub Iran. 2020 (12 Nov);34:154. https://doi.org/10.34171/mjiri.34.154

\section{Introduction}

Osteoporosis is a skeletal disease characterized by a reduction in bone mass and microstructures and a decline in bone tissue that is associated with increased fragility and increased risk of fracture (1). Osteoporosis is one of the

Corresponding author:Dr Aziz Rezapour, rezapour.a@iums.ac.ir

1. Department of Health Economics, School of Health Management and Information Sciences, Iran University of Medical Sciences, Tehran, Iran

2. Health Management and Economics Research Center, School of Health Management and Information Sciences, Iran University of Medical Sciences, Tehran, Iran main threats of aging, and its prevalence among people aged over 50 years is $30 \%$ in women and $15 \%$ in men (2). Osteoporosis is characterized by a decrease in bone mineral

$\uparrow$ What is “already known” in this topic:

Osteoporosis can result in painful fractures. Risk factors for osteoporosis include aging, being female, low body weight, low sex hormones or menopause, smoking, and some medications. Osteoporosis and consequent fractures not only have a major impact on the health and quality of life but also impose a significant economic burden on the health system of countries.

\section{$\rightarrow$ What this article adds:}

This study indicated that the cost of osteoporosis was related to fractures caused by the disease that occurs in the elderly, and the main causes of costs were hospital and surgical costs. Given that treating people with osteoporosis and related fractures are often expensive. Prevention of this disease can significantly reduce the costs incurred by the health system. 
content along with bone matrix, so that bone loss is reduced, but bone composition remains normal (3).

Bone fractures are the most important complication of osteoporosis (1). Fractures lead to increased mortality, disability, and increased medical costs. Osteoporosis is more common in women than in men. The disease is manifested when bone fractures occur, especially in the vertebral and pelvic areas (4).

In 2010, the estimated number of osteoporotic fractures in the European Union was 3.5 million cases, which included 620,000 cases of hip fractures, 520,000 cases of spine fractures, 560,000 cases of forearm fractures, and $1,800,000$ cases of other types of fracture. The number of annual cases of osteoporotic fractures is expected to reach 4.5 million cases by 2025 (5).

Osteoporosis and its fractures not only have a major impact on health and quality of life but also impose a significant economic burden on the health system (1). The economic costs of a disease can be used to estimate the burden of that disease. The costs in the economy are divided into two groups, including direct and indirect costs. The direct costs are the treatment costs, and the indirect costs are the costs associated with days off from work or school due to illness (6). The costs associated with osteoporosis in the European Union in 2010 were estimated to be 37 billion euros, more than $70 \%$ of which is related to the costs of fractures caused by osteoporosis (2). In 2005, the direct medical costs of osteoporosis in the United States were estimated to be 13.7 to 20.3 billion dollars. It is also projected that by 2025, more than 3 million cases of osteoporotic fracture will occur annually, with an estimated cost of 25.3 billion dollars $(7,8)$.

Among the different components of health care systems, hospitals are facing a shortage of resources as a challenge, and every type of shortage of resources leads to a competition. Under such a condition and competition, only the organizations that could reduce the costs while paying attention to the quality of services provided can be successful. Therefore, cost information in the hospital can be of great value in optimizing resource allocation, modifying budgets, reducing waste costs, and making more efficient use of available resources. The objective of every cost detection and cost management system is to provide accurate and practical information to help organizations deliver quality goods and services under a competitive setting (9).

The prevalence of osteoporosis increases with aging that is due to decreased bone tissue. Due to the decline of ovarian function in women during the post-menopausal period, the loss of bone mass is accelerated, and as a result, most women have the indications for the diagnosis of osteoporosis at the age of 70-80 years (10).

Since the population of most Asian countries is aging, the incidence of fractures due to osteoporosis is also increasing in these countries. More than 50\% of hip fractures are projected to occur in Asian countries by 2050 (5). The average prevalence of osteoporosis in Iran in 2012 was 17\% (11).

Osteoporosis is preventable and treatable, but since it is a latent disease, it is usually undetectable until the final stages (12). Osteoporosis is a complex disease that is influenced by several factors, some of which are uncontrollable, such as age, sex, race, family history, menopause, and some other factors such as weight, mobility, nutrition, and smoking (10). Bone ability to cope with a fracture is dependent on several factors including bone mass, bone shape, and intrinsic characteristics of bone (13). There are several recommendations for preventing osteoporosis; for instance, it is recommended to adopt a diet high in calcium and vitamin $\mathrm{D}$ and have a daily intake of calcium-rich foods, especially low-fat and pasteurized dairy products (10). Different treatment strategies such as behavioral changes, use of pelvic protectors and analgesics, and the use of muscle relaxants, heat, massage, and rest can reduce the risk of osteoporotic fractures (10). The risk and frequency of fractures vary by race, so they should be investigated individually in every population group (14).

Half of women and one-fifth of men aged over 50 years are at risk of fractures in their life. The serious complications of fracture are mortality, pain, and loss of quality of life (15). The rate of mortality from hip and spine fractures is approximately $20 \%$. The total DALY due to osteoporotic fractures in 2000 was 5.8 million years, which is somewhat higher than that of hypertension and rheumatism. The economic burden on this disease in women is higher than that in men, with $64 \%$ of DALY observed in women. In a study on osteoporosis burden in Iran in 2001, the years of life lost (YLL) due to osteoporotic fractures was 32,375 years for hip fractures, 3,493 years for spine fractures, and 158 years for forearm fractures. In total, osteoporosis resulted in 36,027 years of life lost due to premature death and disability (16).

As mentioned above, due to increased life expectancy and an increasing percentage of the elderly population in recent years, the incidence and prevalence of osteoporosis and related fractures have been increasing, and this disease has become one of the most common diseases. In addition, advances in medical technology and the introduction of new and sometimes costly preventive and therapeutic methods have made the disease economically striking. Studies carried out in Western and some Asian countries have shown that osteoporosis imposes a significant economic burden on communities, and its related costs are rising in most countries, especially Asian countries, including Iran. Given the important role of information about the costs and economic aspects of osteoporosis in making policies and planning measures for the prevention and management of this disease, this study systematically investigated the evidence and data on the costs of osteoporosis in the world. The data was analyzed through reviewing existing studies, and it aimed at better assessing the economic burden of osteoporosis in different countries around the world.

\section{Methods}

\section{Review of the literature}

Identification of studies: This study was conducted as a systematic review to examine the economic burden of osteoporosis in the world. First, all relevant terms related to economic burden and osteoporosis were identified. The search strategy was designed by utilizing keyword combinations. Search keywords, search terms, synonyms, and combinations with OR and AND operators were used to 
improve the sensitivity of the search. The related literature was then searched in related journal databases and references based on the search strategy. Screening was performed through considering the inclusion and exclusion criteria and relevant articles were identified. Finally, the required data were extracted from the selected articles and the evidence was compared and summarized.

To find suitable studies for analysis, several databases including PubMed, Embase, Scopus, Web of Science, ProQuest, and Cochrane were searched using the keywords of economic burden, cost of illness, and osteoporosis. The timeframe selected for searching articles was from 1980 to 2018.

Search strategy: The search strategy for PubMed database was as follows:

"1-Cost of Illness " [Title/Abstract] OR "Economic burden"[Title/Abstract] OR "Disease Costs"[Title/Abstract] OR "Cost of Sickness"[Title/Abstract] OR "Sickness Costs"[Title/Abstract] OR "Costs of Disease"[Title/Abstract] OR "Burden of Illness"[Title/Abstract] OR "Illness Burden"[Title/Abstract] OR "Illness Burdens"[Title/Abstract] OR "Cost of Disease"[Title/Abstract] OR "Economic Burden of Disease"[Title/Abstract] OR "Disease Cost"[Title/Abstract] OR "Illness Cost"[Title/Abstract] OR "Illness Costs"[Title/Abstract] OR "Sickness Cost"[Title/Abstract]) AND osteoporosis"[Title/Abstract] OR "Post-Traumatic Osteoporosis"[Title/Abstract] OR "Senile Osteoporosis"[Title/Abstract] OR "Age-Related Bone Loss"[Title/Abstract] OR "Age-Related Bone Losses"[Title/Abstract] OR "Age-Related Osteoporosis"[Title/Abstract] OR "Age Related Osteoporosis"[Title/Abstract]

\section{Inclusion and exclusion criteria}

Inclusion criteria: In this study, inclusion criteria were as follows: economic burden of osteoporosis, including direct and indirect costs; studies with available full-text papers; scientific research and studies written in English and published between 1980 to 2018 years.

Exclusion criteria: This study excluded papers that did not meet the following criteria: studies written in languages other than English; and all protocols, conference abstracts, review articles, and letters to the editor.

\section{Study selection}

After searching for different databases, all the detected articles were imported into EndNote software and the duplicates were removed. The rest of the papers were independently reviewed individually by two experts in this field. At this stage, the PRISMA principles were followed to retrieve the final articles in the first stage the title and abstract of the papers were reviewed and on the basis of the inclusion and exclusion criteria mentioned above, the relevant papers were selected. Then, if the full text of the selected studies was accessible, the studies were carefully reviewed and the final papers were selected. In each of these stages, in case of disagreement between the two researchers, the papers were reviewed by a third researcher. performed using a data extraction form. In addition, in order to compare costs in different studies, all the costs were converted to dollars based on purchasing power parity index in 2018. For each study investigated in the final step, a sheet was designed in the Excel file and the basic information including the author's name, article title, year of publication, country of origin, study design and duration of the study, study population, study outlook, direct costs, and indirect costs were entered into each sheet.

\section{Quality assessment}

In this systematic review, all studies related to the cost of osteoporosis, which involves direct, indirect, and intangible costs in a variety of fractures were considered. In this study, there was a time limit and only papers that are in English have been examined. This systematic review has been reported based on the PRISMA checklist (17).

\section{Results}

The initial results of the search in the databases provided a total of 3113 articles. Of these, after removing duplicates, 1989 articles included in the study, which was reduced to 612 papers after reviewing the title. Then, the abstracts of the articles were reviewed and 163 articles met the inclusion criteria. The fulltexts of the 163 articles were reviewed, out of which 135 were selected based on the inclusion and exclusion criteria. Finally, 28 papers were selected for a more meticulous examination. No new relevant studies were found in the review of the references of the finally selected articles (Fig. 1).

The quality of the 28 selected studies was assessed using the PRISMA checklist. To avoid bias when evaluating the quality of the selected papers, the researchers had become blinded to the basic information on the article, such as the author's name, country, and year of publication. The results of the quality assessment of the studies were acceptable and no study was excluded based on the results of the quality assessment of the study. The results of the quality assessment of the studies were presented on the basis of the PRISMA checklist. After evaluating the quality of data of the selected articles, data were extracted using a data extraction form and arranged in a table format. Because studies could only be categorized by cost types, the data were categorized by cost types (direct, indirect, etc.).

\section{Direct costs}

Studies that only investigated direct costs had been published between 1993 and 2017. Most of the studies in this category were conducted in developed countries such as Canada, Germany, and the United States. The sample sizes were different. The cost perspectives in the reviewed studies included the perspective of patients, community, government, etc. As presented in Table 1, the studies in this category reported direct costs, costs per case of fracture, average cost, total cost, or annual cost of fracture for the country under the study (Table 1). 

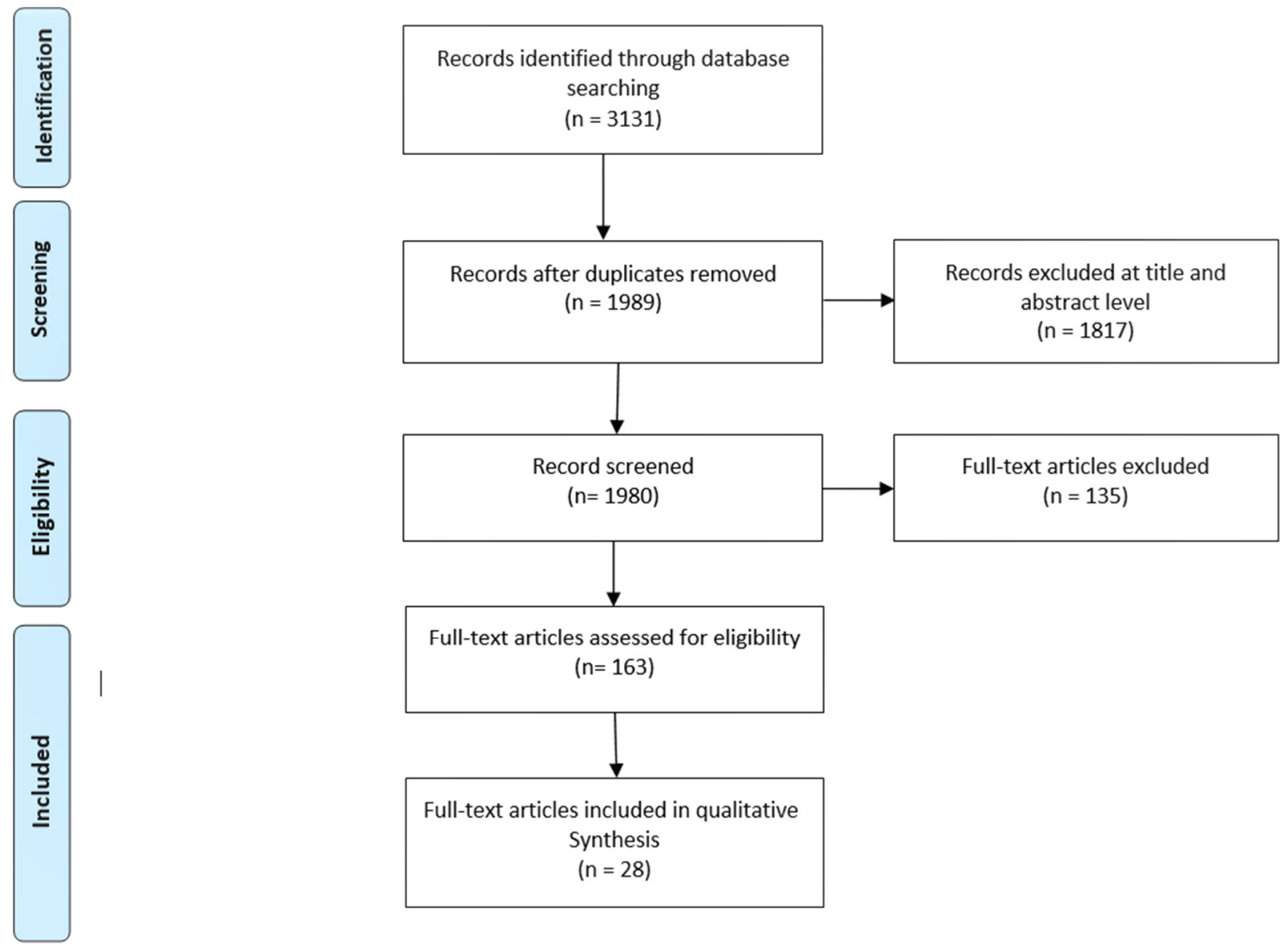

Fig. 1. Literature search flow diagram

\section{Indirect and direct costs}

Among the selected studies, there was no study that reported only indirect costs. As presented in Table 2, some of the selected studies had reported the results of direct and indirect costs together and had been published between 2002 and 2017 (Table 2).

The twenty-eight articles selected for the study had been published between 1980 and 2018. Of all, 4 articles were from USA $(27,28,29,32)$, three articles were from Canada $(22,23,43)$, two articles were from South Korea $(21,34)$, two articles were from Portugal $(31,43)$, and two articles were from Germany $(1,26)$. In addition, there was one article from each of the countries of Belgium, China, California, Sweden, Netherlands, Mexico, Australia, Singapore, Slovenia, Romania, France, Turkey, England, Iran, and Latin America. Of all, five articles reported retrospective research, 3 articles reported prospective research, 2 articles reported bottom-up costing, 2 articles reported prevalencebased investigation, 2 articles reported top-down costing, one article reported observational research, and one article had a descriptive design. The sample size ranged from 67 to $30,243,445$ cases. In addition, 18 out of 28 studies had been carried out after 2010, indicating the increasing importance of the disease in recent years. Target groups in these studies had various fractures including hip, spine, wrist, shoulder, ankle, and rib fractures; except for five studies that did not investigate fractures $(30,22,24,27,41)$, hip fracture had been investigated in all studies and was reported as a costly complication. Cost data were mainly collected from hospital bills and patient records. These studies included direct medical costs, direct non-medical costs, and indirect costs, and in most studies, direct medical costs, including the costs of outpatient services, drugs, and surgeries were included. The cost components of most studies were clearly stated, although the descriptions varied widely among studies. Indirect costs were also reported in 12 studies. Other types of costs, including home care costs, equipment, etc. were also reported in some studies. In four studies, indirect costs were higher than direct costs. Qu et al.'s study estimated indirect costs such as early retirement and job loss (40), while Kim et al.'s study estimated the rate of lost productivity (34). Only Chang's study reported incremental costs of treatment (21). Since all the studies included patient-level data, it was not useful to conduct sensitivity analysis.

The average cost of treatment of osteoporosis was US \$ $5,258,741$, which accounts for 20 percent of the GDP of countries in 2018. The studies conducted in Singapore, Iran, and Korea reported less than $20 \%$ of the GDP per capita for osteoporotic care $(18,34,35)$, while in most other studies, it accounted for more than $30 \%$ of the GDP.

Cost components analysis showed that hospitalization and surgery accounted for the largest part of the total costs. The length of hospital stays varied from 2 to 89 days. In 
Table 1. Characteristics of selected articles included in the systematic review/Direct costs of osteoporosis

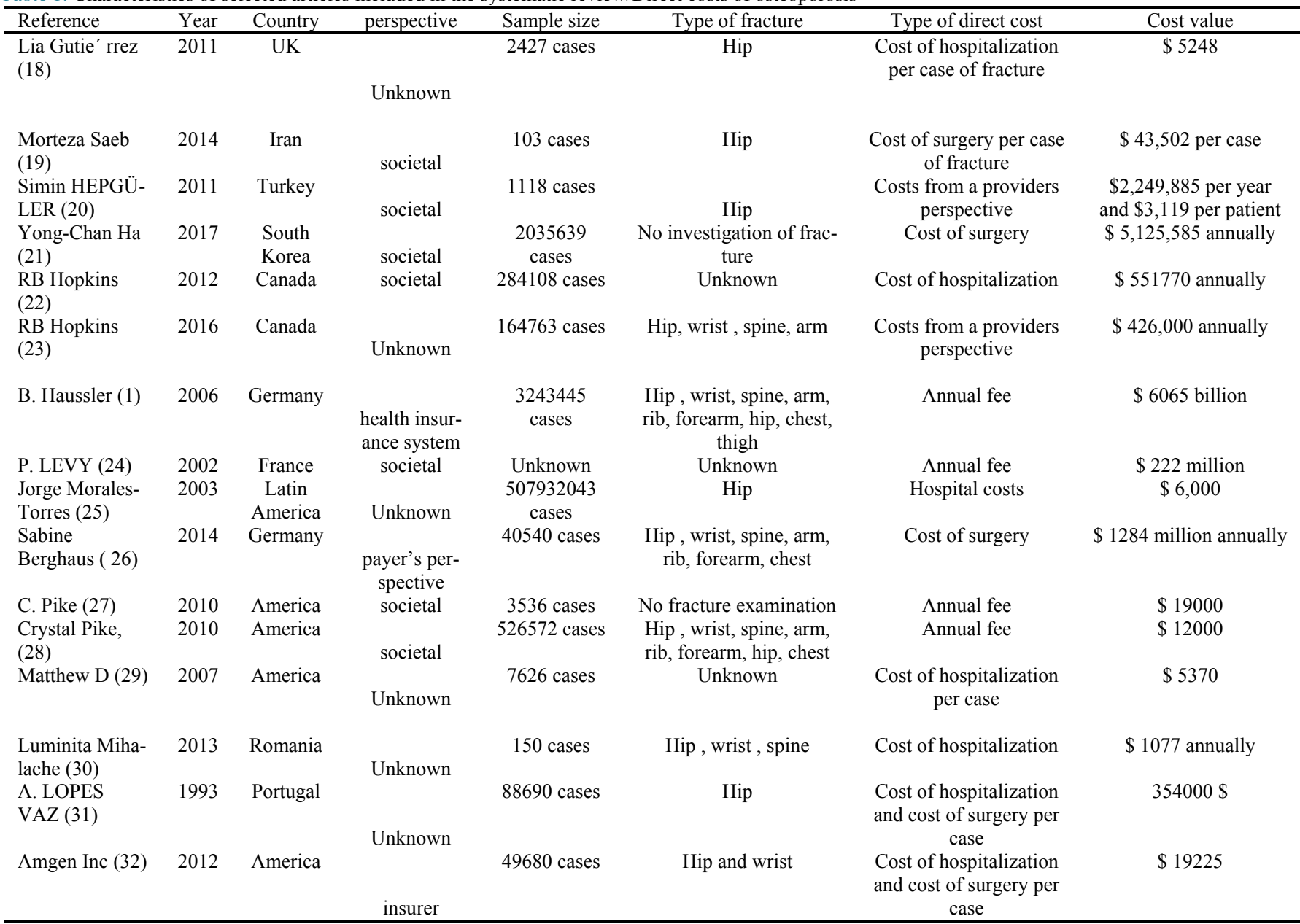

studies that reported direct non-medical costs $(n=9)$, the average transportation cost was $\$ 20$, indicating a small proportion of the total costs. As reported in Qu's study, the indirect costs of job loss, early retirement, and unemployment were $\$ 11, \$ 48$, and $\$ 60$, respectively (40).

\section{Discussion}

This review is the first to explore the economic burden of osteoporosis, including direct and indirect costs. We found large heterogeneity with respect to the investigated sector of the health care system and the cost components; the quality of studies was mostly mediocre. Most studies did not report hospitalization days. The original studies reported two main drivers of increased direct costs: Cost of hospitalization and cost of surgery. Because of the elderly people with osteoporosis and its fractures, the cost of hospitalization was a major part of these studies. Being elderly increases the length of hospital stay and consequently increases the cost of hospitalization.

South Korea to treat this disease incurs 645 million dollars for direct costs and 647 million dollars for indirect costs (34). The annual cost of outpatient treatment in Australia was reported to be 350 million dollars in 2008 for the direct cost (16). In Portugal and the US, annual costs of hospital and surgical services range from 354000 to 19000 dollars $(31,32)$

Based on the results of studies investigated in this systematic review, regardless of the approach of cost detection used by different studies, the average cost of each case of treatment is reported to be between 5000 dollars and 6500 billion dollars. To justify this finding, it might be said that many studies on osteoporosis have been conducted in developed countries where the cost of inputs is relatively high in such countries and they usually follow the proper treatment procedures and guidelines.

The majority of studies investigated in this systematic review, which investigated the costs of osteoporosis, had been conducted in developed countries. Concerning osteoporosis with fractures, regardless of the type of detection cost, the USA spends between 5,000 and 19000 dollars for each case of fracture $(27,28,29,32)$. Also, in the US studies only direct costs were reported. In the UK, 5248 dollars is spent per case for the treatment of osteoporotic fractures (18).

Our findings showed that few studies have fully investigated the total costs (direct and indirect costs) to estimate the economic burden of osteoporosis, and this limitation reduces investment in health care resources to prevent the disease. In addition, although all the studies aimed to determine the economic burden of osteoporosis fractures, there 
Table 2. Characteristics of selected articles included in the systematic review/ indirect and direct costs of osteoporosis

\begin{tabular}{|c|c|c|c|c|c|c|c|}
\hline Reference & Year & $\begin{array}{l}\text { Coun- } \\
\text { try }\end{array}$ & $\begin{array}{l}\text { Perspec- } \\
\text { tive }\end{array}$ & Sample size & $\begin{array}{l}\text { Type of frac- } \\
\text { ture }\end{array}$ & Type of cost & Cost value \\
\hline $\begin{array}{l}\text { Biljana Dzaj- } \\
\text { kovska (33) }\end{array}$ & 2007 & $\begin{array}{l}\text { Slove- } \\
\text { nia }\end{array}$ & Social & 355100 cases & $\begin{array}{l}\text { Hip, wrist, } \\
\text { spine }\end{array}$ & $\begin{array}{l}\text { Costs from a community } \\
\text { perspective per case }\end{array}$ & $\begin{array}{c}\$ 9 \text { million in direct costs } \\
\text { and } \$ 10 \text { million in indirect } \\
\text { costs }\end{array}$ \\
\hline $\begin{array}{l}\text { Jinhyun Kim } \\
\text { (34) }\end{array}$ & 2016 & $\begin{array}{l}\text { South } \\
\text { Korea }\end{array}$ & Social & 244798 cases & $\begin{array}{l}\text { Hip, wrist, } \\
\text { spine, arm, } \\
\text { forearm }\end{array}$ & $\begin{array}{l}\text { Cost per case for hospitali- } \\
\text { zation, medical require- } \\
\text { ments , medication, person- } \\
\text { nel }\end{array}$ & $\begin{array}{c}\text { \$ } 645 \text { million in direct costs } \\
\text { and } \$ 647 \text { million in indi- } \\
\text { rect costs }\end{array}$ \\
\hline $\begin{array}{l}\text { Charmaine } \\
\text { Shuyu Ng } \\
(35)\end{array}$ & 2017 & $\begin{array}{l}\text { Singa- } \\
\text { pore }\end{array}$ & $\begin{array}{l}\text { Hospital's } \\
\text { and } \\
\text { patient's }\end{array}$ & 67 cases & $\begin{array}{l}\text { Hip, wrist, } \\
\text { spine }\end{array}$ & Direct costs per case & $\begin{array}{l}\text { \$ } 5545 \text { in direct costs and \$ } \\
3697 \text { in indirect costs }\end{array}$ \\
\hline $\begin{array}{l}\text { Hans Peter } \\
\text { Dimai (22) }\end{array}$ & 2012 & $\begin{array}{l}\text { Aus- } \\
\text { tralia }\end{array}$ & Societal & 119911 cases & $\begin{array}{l}\text { Hip, arm, } \\
\text { spine, fore- } \\
\text { arm, rib }\end{array}$ & Direct and indirect costs & $\begin{array}{c}\$ 550 \text { million in direct costs } \\
\text { and } \$ 253 \text { million in indi- } \\
\text { rect costs }\end{array}$ \\
\hline P. Clark (36) & 2008 & Mexico & $\begin{array}{l}\text { Patient and } \\
\text { provider }\end{array}$ & 493 cases & Hip & $\begin{array}{c}\text { Direct and indirect costs per } \\
\text { case }\end{array}$ & $\begin{array}{l}\$ 31000 \text { in direct costs and } \\
\$ 97000 \text { in indirect costs }\end{array}$ \\
\hline $\begin{array}{l}\text { DA Eekman } \\
(37)\end{array}$ & 2014 & $\begin{array}{l}\text { Nether- } \\
\text { lands }\end{array}$ & Societal & 116 cases & $\begin{array}{l}\text { Hip, arm, } \\
\text { spine, fore- } \\
\text { arm, rib }\end{array}$ & $\begin{array}{c}\text { Direct costs (hospitalization } \\
\text { and surgery) and indirect } \\
\text { costs }\end{array}$ & $\begin{array}{l}\text { \$328 million in annual di- } \\
\text { rect costs and \$ } 437 \text { million } \\
\text { in annual indirect costs }\end{array}$ \\
\hline $\begin{array}{l}\text { Oskar Ström } \\
(38)\end{array}$ & 2008 & Sweden & Societal & $\begin{array}{l}684 \text { patients } \\
\text { from } 7 \text { hospi- } \\
\text { tals }\end{array}$ & $\begin{array}{l}\text { Hip, wrist } \\
\text { spine }\end{array}$ & $\begin{array}{c}\text { Costs of diagnosis and treat- } \\
\text { ment }\end{array}$ & $\begin{array}{c}\$ 6566 \text { in annual direct } \\
\text { costs and \$ } 150 \text { in indirect } \\
\text { costs }\end{array}$ \\
\hline W. Max (39) & 2002 & $\begin{array}{l}\text { Califor- } \\
\text { nia }\end{array}$ & & 10254774 cases & $\begin{array}{l}\text { Hip, arm, } \\
\text { spine }\end{array}$ & $\begin{array}{l}\text { Direct costs and indirect } \\
\text { costs }\end{array}$ & $\begin{array}{l}\$ 3 \text { million in direct costs } \\
\text { and } \$ 4353 \text { in indirect costs }\end{array}$ \\
\hline B. Qu (40) & 2014 & China & $\begin{array}{l}\text { Societal } \\
\text { Societal }\end{array}$ & 938 cases & $\begin{array}{l}\text { Hip, arm, } \\
\text { spine }\end{array}$ & $\begin{array}{l}\text { Direct costs and indirect } \\
\text { costs }\end{array}$ & $\begin{array}{l}\text { \$ } 7860 \text { in direct costs and \$ } \\
410 \text { in indirect costs }\end{array}$ \\
\hline $\begin{array}{l}\text { V. Rabenda } \\
\text { (41) }\end{array}$ & 2006 & $\begin{array}{l}\text { Bel- } \\
\text { gium }\end{array}$ & $\begin{array}{c}\text { Payer's } \\
\text { perspective }\end{array}$ & 1811 cases & Unknown & $\begin{array}{l}\text { Direct costs and indirect } \\
\text { costs }\end{array}$ & $\begin{array}{c}\$ 52 \text { in annual direct costs } \\
\text { and } \$ 40 \text { in indirect annual } \\
\text { costs }\end{array}$ \\
\hline $\begin{array}{l}\text { J. E. Tarride } \\
(42)\end{array}$ & 2011 & Canada & Social & 12706 cases & $\begin{array}{l}\text { Hip, arm, } \\
\text { spine, fore- } \\
\text { arm, rib }\end{array}$ & $\begin{array}{l}\text { Direct costs and indirect } \\
\text { costs }\end{array}$ & $\begin{array}{l}\$ 200 \text { billion in annual di- } \\
\text { rect costs and } \$ 115 \text { million } \\
\text { in annual indirect costs }\end{array}$ \\
\hline $\begin{array}{l}\text { A. Marques } \\
(43)\end{array}$ & 2015 & $\begin{array}{l}\text { Portu- } \\
\text { gal }\end{array}$ & Societal & 186 cases & Hip & $\begin{array}{l}\text { Direct costs and indirect } \\
\text { costs }\end{array}$ & $\begin{array}{l}\$ 3800 \text { annual direct costs } \\
\text { and \$ } 194 \text { annual indirect } \\
\text { costs }\end{array}$ \\
\hline
\end{tabular}

were many differences in the cost estimation methods that prevent the direct comparison of results.

In the present studies, economic evaluations of indirect and intangible costs were very limited, which leads to uncertainty in the estimation of the economic burden of osteoporosis. Although productivity loss due to absenteeism might be very infrequent in elderly patients, the indirect costs incurred by other family members can be significant.

\section{Conclusion}

Because of the recruitment of skilled personnel, surgical procedures, expensive medications, and long-term treatment service delivery and hospital stays, the process of treating people with osteoporosis and related fractures is often expensive. Prevention of this disease can significantly reduce the costs incurred by the health system, especially in developing countries where osteoporosis is common and associated with fractures. Developed countries, such as the United States, provide treatment for osteoporosis and associated fractures at high costs that is due to the high cost of inputs used in the treatment process. The current systematic review study included a cost detection method that included both direct medical costs and direct non-medical costs, and future studies that examine other costs may reveal newer dimensions of disease burden and more cost-effective methods of osteoporosis therapies. Most studies focusing on direct costs had been conducted in developed countries such as the United States and Canada and they had not considered non-monetary costs of care (such as lost quality of life), which may be an important issue in future studies. This systematic review study undoubtedly provides valuable information about the osteoporosis burden for individuals and communities, and also shows that many resources are being spent on this disease in the world. Some of the studies investigated in this systematic review have shown that the provision of osteoporosis prevention services is less expensive than its treatment. Therefore, it is necessary to work with providers and payers to provide preventive care, especially in developing countries where osteoporosis is prevalent. Such services can be included in the basic services package and provided at lower costs in hospitals or designated centers. 


\section{Limitations}

In this study, it was tried to avoid any bias by conducting a comprehensive and systematic search. However, the failure to follow a standard cost detection approach in the selected studies had reduced the consistency of the reported results; hence, it might prevent the analysis of the reported results on the basis of different dimensions. The papers investigated in this systematic review had reported costs in different years and on the basis of different countries' currencies and examined different cost items. To cover this limit, all costs were reported in 2018. In addition, some studies have reported the costs in a general form while some other studies have reported the details on costs; thus, in some cases, it was not possible to compare them.

\section{Conflict of Interests}

The authors declare that they have no competing interests.

\section{References}

1. Haussler B, Gothe H, Gol D, Glaeske G, Pientka L, Felsenberg D. Epidemiology, treatment and costs of osteoporosis in Germany-the Bone EVA Study. Osteoporos Int. 2007;18(1):77-84

2. Zamani B, Ebadi S, Ahmadvand A, Mousavi G. The Frequency of Osteoporosis in hip fracture following minor trauma and the resulting mortality rate and direct treatment costs in patients over 45 years old in Kashan Naghavi Hospital during 2005-2007. J Kerman Univ Med Sci. 2010;17(2):137-44.

3. Aghamohammadzadeh N, Najafipour F, Bahrami A, Niafar M, Baglar L, Hajiegrary $\mathrm{H}$, et al. Evaluation of effective factors in decreased bone density in patients with osteoporosis and osteopenia. Gorgan Univ Med Sci. 2009;11(2):61-7.

4. Ahmadzadeh A, Rajaee A, Rezaian S, Tojari F, Emam M, Moslemizadeh M. Comparative evaluation of the OST and SCORE for prediction of osteoporosis in post-menopausal women. Pajoohandeh. 2010;15(4):165-70.

5. Hernlund E, Svedbom A, Ivergard M, Compston J, Cooper C, Stenmark $\mathrm{J}$, et al. Osteoporosis in the European Union: medical management, epidemiology and economic burden. Arch Osteoporos. 2013;8(12):136.

6. Heydarpour F, Akbari Sari A, Mohebali M, Bokaie S. Economic Burden of Cutaneous and Visceral Lishmaniasis in Iran in 2013. Iran J Epidemiol. 2017;12(4);1-13.

7. Burge R, Dawson-Hughes B, Solomon DH, Wong JB, King A, Tosteson A. Incidence and economic burden of osteoporosis-related fractures in the United States, 2005-2025. J Bone Miner Res. 2007;22(3):465-75

8. Roche J, Wenn RT, Sahota O, Moran CG. Effect of comorbidities and postoperative complications on mortality after hip fracture in elderly people: prospective observational cohort study. BMJ. 2005;331(7529):1374.

9. Bangeman TO. Shared Services in Finance and Accounting. British: Gower Publishing Company; 2005. pp .39-64.

10. Hodsman A, Papaioannou A, Cranney A. Clinical practice guidelines for the use of parathyroid hormone in the treatment of osteoporosis. CMAJ. 2006;175(1):48-51.

11. Irani AD, Poorolajal J, Khalilian A, Esmailnasab N, Cheraghi Z Prevalence of osteoporosis in Iran: A meta-analysis. J Res Med Sci .2013;18(9):759-66.

12. Naghavi M, Abolhassani F, Pourmalek F, Moradi Lakeh M, Jafari N, Vaseghi S, et al. The burden of disease and injury in Iran 2003. Popul Health Metr. 2009;7(1):9.

13. Dempster DW. Osteoporosis and the burden of osteoporosis-related fractures. Am J Manag Care. 2011;17(6):S164-9.

14. Larijani B, Moayyeri A, Keshtkar A, Hossein-Nezhad A, Soltani A, Bahrami A, et al. Peak bone mass of Iranian population: The Iranian multicenter osteoporosis study. J Clin Densitom. 2006;9(3):367-74.

15. Maghbooli Z, Hossein-nezhad A, Jafarpour M, Noursaadat S, Ramezani M, Hashemian R, et al. Direct costs of osteoporosis-related hip fractures: protocol for a cross-sectional analysis of a national database. BMJ Open. 2017;7(4):e014898.

16. Dimai HP, Redlich K, Peretz M, Borgstrom F, Siebert U, Mahlich J. Economic burden of osteoporotic fractures in Austria. Health Econ Rev. 2012;2(1):12.

17. Moher D, Shamseer L, Clarke M, Ghersi D, Liberati A, Petticrew M, et al. Preferred reporting items for systematic review and met analysis protocols (PRISMA-P) 2015 statement. Syst Rev. 2015;4(1):1.

18. Gutiérrez L, Roskell N, Castellsague J, Beard S, Rycroft C, Abeysinghe S, et al. Study of the incremental cost and clinical burden of hip fractures in postmenopausal women in the United Kingdom. J Med Econ. 2011;14(1): 99-107.

19. Saeb M, Beyranvand M, Basiri Z, Haghparast-Bidgoli H. The hospital resource utilization associated with osteoporotic hip fractures in Kermanshah, Iran. J Inj Violence Res. 2014;6(1):16.

20. Hepguler S, Cetin A, Degar C, Erkent U. Osteoporotic hip fracture costs in the elderly Turkish population. Acta Orthop Traumatol Turc. 2011;45(5):316-25.

$21 \mathrm{Ha}$ YC, Kim HY, Jang S, Lee YK, Kim TY. Economic burden of osteoporosis in South Korea: claim data of the National Health Insurance Service from 2008 to 2011. Calcif Tissue Int. 2017;101 (6):623-30

22. Hopkins RB, Tarride JE, Leslie WD, Metge C, Lix LM, Morin S, et al. Estimating the excess costs for patients with incident fractures, prevalent fractures, and nonfracture osteoporosis. Osteoporos Int. 2013;24(2):581-93.

23. Hopkins RB, Burke N, Von Keyserlingk C, Leslie WD, Morin SN, Adachi JD, et al. The current economic burden of illness of osteoporosis in Canada. Osteoporos Int. 2016;27(10):3023-32.

24. Levy P, Levy E, Audran M, Cohen-Solal M, Ardellone PF, Le Parc JM. The cost of osteoporosis in men: the French situation. Bone. 2002;30(4):631-36

25. Morales-Torres J, Gutierrez-Urena S, Osteoporosis Committee of Pan-American League of Associations for Rheumatology. The burden of osteoporosis in Latin America. Osteoporos Int. 2004;15(8):625-32.

26. Berghaus S, Müller D, Gandjour A, Civello D, Stock S. Osteoporosis in German men: a cost-of-illness study. Expert Rev Pharm Out. 2015;15(3):531-37.

27. Pike C, Birnbaum HG, Schiller M, Swallow E, Burge RT, Edgell ET. Economic burden of privately insured non-vertebral fracture patients with osteoporosis over a 2-year period in the US. Osteoporos Int 2011;22(1):47-56.

28. Pike C, Birnbaum HG, Schiller M, Swallow E, Burge RT, Edgell ET. Direct and indirect costs of non-vertebral fracture patients with osteoporosis in the US. Pharmacoeconomics. 2010;28(5):395-09.

29. Rusculp MD, Long SR, Wang S, Schoenfeld MJ, Meadows, ES. Economic burden of osteoporosis-related fractures in Medicaid. Value Health. 2007;10(2):144-52.

30. Mihalache L, Berghea F, Botez P, Dumitru C, Grigorie D, Ionescu R, et al. The cost of osteoporotic fractures in the Romanian postmenopausal women population. Value Health. 2013;16(7):619-4.

31. Vaz A. Lopes. Epidemiology and costs of osteoporotic hip fractures in Portugal. Bone. 1993;21(14):9-13.

32. Viswanathan HN, Curtis JR, Yu J, White J, Stolshek BS, Merinar CN, et al. Direct healthcare costs of osteoporosis-related fractures in managed care patients receiving pharmacological osteoporosis therapy. Appl Health Econ Hea. 2012;10(3):163-73.

33. Dzajkovska B, Albert I, Wertheimer, Ales Mrhar. The burden-ofillness study on osteoporosis in the Slovenian female population. Pharm World Sci. 2007;29(4):404-11.

34. Kim J, Lee E, Kim S, Lee TJ. Economic burden of osteoporotic fracture of the elderly in South Korea: a national survey. Value Health Red Issues. 2016;27(9):36-41.

35. Wong MK, Ching LK, Lim SL, Lo NN. Osteoporotic hip fractures in Singapore--costs and patient's outcome. Ann Acad Med Singapore. 2016;31(1):3-7.

36. Clark P, Carlos F, Barrera C, Guzman J, Maetzel A, Lavielle P, et al. Direct costs of osteoporosis and hip fracture: an analysis for the Mexican healthcare system. Osteoporos Int. 2008;19(3):269-76.

37. Eekman DA, Ter Wee MM, Coupe VMH, Erisek-Demirtas S, Kramer MH, Lems WF. Indirect costs account for half of the total costs of an osteoporotic fracture: a prospective evaluation. Osteoporos Int. 2014;25(1):195-04.

38. Oskar S, Borgstrom F, Zethraeus N, Johnell O, Lidgren L, Ponzer S, et al. Long-term cost and effect on quality of life of osteoporosis-related 
fractures in Sweden. Acta orthopaedica. 2008;79(2):269-80.

39. Max W, Sinnot P, Kao C, Sung HY, Rice DP. The burden of osteoporosis in California, 1998." Osteoporos Int. 2002;13(6):493-500.

40. Qu B, Ma Y, Yan M, Wu HH, Fan L, Liao DF, et al. The economic burden of fracture patients with osteoporosis in western China. Osteoporos Int. 2014;25(7):1853-60.

41. Rabenda V, Manette C, Lemmens R, Mariani AM, Struvay N, Reginster JY. The direct and indirect costs of the chronic management of osteoporosis: a prospective follow-up of 3440 active subjects. Osteoporos Int. 2006;17(9):1346-52.

42. Tarride JE, Hopkins RB, Leslie WD, Morin S, Adachi JD, Papaioannou A, et al. The burden of illness of osteoporosis in Canada. Osteoporos Int. 2012;23(11):2591-2600.

43. Marques A, Lourenço Ó, Da Silva JAP. The burden of osteoporotic hip fractures in Portugal: costs, health related quality of life and mortality. Osteoporos Int. 2015;26(11):2623-30. 